\title{
Clinical and laboratory observations on patients from a nursing home outbreak of verotoxin- producing E coli (0157:H7 strain)
}

Melvin R. Bel.sheim, MD, James Lewis, MD, William Brien, MD

ABSTRACT: Beginning on September 7, 1985, an outbreak of bloody diarrhea affected 53 of 169 residents of a London, Ontario nursing home. The most severely affected patients were transferred to local general hospitals under the care of a number of physicians for investigation and treatment. Overall, 19 patients died during the outbreak. Clinical and laboratory information on the 18 patients admitted to this institution are reported. A majority of these patients had either verotoxin detected in fecal extracts or Escherichia coli 0157: $\mathrm{H} 7$ isolated from their stools. The mor tality rate at this institution exceeded $75 \%$ ( 14 patients). Six patients developed hemolytic uremic syndrome and none of these survived the illness, Can J Gastroenterol 1988; $2(2): 57-59$

Key Words: E coli 0157:H7, Hemolytic uremic syndrome, VTEC, Verotoxin

\section{CLINICAL INFORMATION}

Between September 9 and September $28,1985,18$ seriously ill patients with acute diarrhea were transferred to $\mathrm{St}$ Joseph's Hospital from a local nursing home. Although 17 of the patients had rectal bleeding, only 10 complained of abdominal pain on admission. Information on nursing home transfer forms indicated that 12 patients had a preadmission diagnosis of Alzheimer's disease or dementia and that 16 patients

Department of Medicine, St Joseph's Hospital; and The University of Western Ontario, London, Ontario

Correspondence and reprints: Dr M.R. Belsheim, c/o Department of Medicine, St Joseph's Health Centre, 268 Grosvenor Street, London. Ontario N6A 4V2

Received for publication September 29, 1987. Accepted February 19, 1988

had additional significant health problems. These included atherosclerotic heart disease (seven patients), arthritis (six patients), hypertension (five patients) and cerebrovascular disease (three patients).

All patients initially had negative stool cultures for Campylobacter species, Salmonella species, Shigella species and Clostridium difficile. Special cultures for verotoxin-producing Escherichia coli organisms (VTEC) were then requested and the first positive verotoxin assay was reported on September 15, eight days after the outbreak began. The first positive culture for $E$ coli $0157: \mathrm{H} 7$ was reported on September 18. This organism was ultimately isolated from the stools of nine patients. Verotoxin was identified in fecal extracts from all but one culture-positive patient and in fecal extracts from three additional culturenegative patients (Table 1).

Although 15 patients were found to have an elevated serum creatinine at some point during hospital admission, 12 patients were felt to be clinically dehydrated and 10 patients were anemic on admission (Table 1), a diagnosis of hemolytic uremic syndrome could be 


\begin{tabular}{|c|c|c|c|c|c|c|c|c|c|c|c|c|c|c|c|c|c|c|}
\hline & \multicolumn{18}{|c|}{ Patient } \\
\hline & 1 & 2 & 3 & 4 & 5 & $6^{*}$ & 7 & 8 & 9 & 10 & 11 & 12 & 13 & 14 & 15 & 16 & 17 & 18 \\
\hline Age (years) & 78 & 84 & 87 & 88 & 94 & 78 & 95 & 93 & 95 & 91 & 85 & 84 & 99 & 93 & 89 & 80 & 86 & 92 \\
\hline Rectal bleeding & $x$ & $x$ & $x$ & $x$ & $x$ & $x$ & $x$ & $\mathrm{x}$ & & $x$ & $x$ & $x$ & $x$ & $x$ & $x$ & $x$ & $x$ & $x$ \\
\hline Abdominal pain & $x$ & & & $x$ & $x$ & & & $x$ & & & $x$ & $x$ & $x$ & & $x$ & & & $x$ \\
\hline Anemia & $x$ & $x$ & $\mathrm{x}$ & & & $x$ & $x$ & $x$ & & & $x$ & $x$ & $x$ & & & $x$ & & \\
\hline $\begin{array}{l}\text { Elevated creatinine } \\
\text { Hemolytic-uremic }\end{array}$ & $x$ & $x$ & $x$ & $x$ & & $x$ & $x$ & $x$ & $x$ & $x$ & $x$ & $x$ & $x$ & $x$ & $x$ & & & $x$ \\
\hline syndrome & & $x$ & & $x$ & & & & & & $x$ & $x$ & $x$ & & & & & $x$ & \\
\hline E coli $0157: H 7$ isolated & $x$ & & & & $x$ & & & & & & $x$ & $x$ & $x$ & $x$ & & $x$ & $x$ & $x$ \\
\hline Verotoxin positive & $x$ & & & $x$ & $x$ & $x$ & $\mathrm{x}$ & & & & $x$ & $x$ & $x$ & $x$ & & $x$ & & $x$ \\
\hline Antibiotics received & $x$ & $x$ & & & & $x$ & & $x$ & $x$ & & & $x$ & $x$ & $x$ & $x$ & $x$ & $x$ & \\
\hline Died & $x$ & $x$ & & $x$ & & $x$ & $x$ & & $x$ & $x$ & $x$ & $x$ & $x$ & $x$ & $x$ & $x$ & $x$ & \\
\hline
\end{tabular}

- Malepatient

made with confidence for six patients only (Table 2). The interval from the initial episode of diarrhea to the development of hemolytic uremic syndrome was between five and nine days (mean seven days). The degree of thrombocytopenia and renal dysfunction measured in these patients was quite variable and not all patients had all three features classically associated with this disorder (1). All diagnosed patients had pathologic evidence of glomerular endothelial damage with fibrin deposition (2) and two additional patients without clinical or laboratory evidence of hemolytic uremic syndrome had positive glomerular capillary fibrin staining at autopsy. This phenomenon would suggest that hemolytic uremic syndrome in this setting can present with a variety of findings ranging from asymptomatic lesions to the classical triad of fulminant renal failure, severe thrombocytopenia and microangiopathic hemolysis.

Fourteen of the 18 patients admitted died during the course of their illness. The interval from initial symptomatology to hospital transfer was zero to five days (mean 2.5 days). The interval from first symptom to either discharge or death was two to 36 days (mean 17 days). No factor was identified which appeared to improve patient survival.

Antibiotic treatment was initiated in an uncontrolled fashion on 11 patients from two to 16 days (mean five days) after the onset of diarrhea. Single and combination drugs were used in a variety of treatment regimens. Nine of 14 patients who died received antibiotics as did two of the four survivors. Five of the six hemolytic uremic patients were treated in an uncontrolled fashion with fresh frozen plasma ( 1 to 4 units each) after the diagnosis was established. None of the hemolytic uremic patients survived the illness and all died while in hospital. The age of affected individuals was from 78 to 99 years (mean 88 years). All survivors were greater than 87 years of age and three of the four survivors were greater than 92 years of age.

\section{DISCUSSION}

The association of VTEC organisms with human enteric illness and renal disease is a fairly recent phenomenon. In 1977, strains of toxin-producing $E$ coli were described which produced a distinctive cytotoxic effect in tissue culture on Vero cells obtained from African green monkey kidnies (3). The toxin identified was termed verotoxin. $E$ coli 0157:H7 has been incriminated as the probable cause of a number of sporadic cases and outbreaks of hemorrhagic colitis in the United States and Canada beginning in 1982 (4-9). The classification system for $E$ coli organisms has recently undergone a major revision with these organisms now referred to as enterohemorrhagic E coli (EHEC) (10). Recent information suggests that the toxin elaborated by these organisms is similar to Shiga toxin produced by Shigella dysenteriae and that at least three distinct subtypes exist (11).

The hemolytic uremic syndrome was first described in 1955 (12). Since that time, a number of inciting events have been implicated in its etiology (13) with $S$ dysenteriae endotoxin being one of the first products from an infectious agent implicated (14). In 1983, Karmali and associates $(15,16)$ first reported sporadic cases of hemolytic uremic syndrome which appeared to be linked to VTEC infections. A subsequent article reported evidence of VTEC infection from at least six different 0 serogroups in 24 of 40 pediatric-aged hemolytic uremic patients (17). Neill and associates (18) reported the association of $E$ coli $0157: \mathrm{H} 7$ with hemolytic uremic syndrome in adult patients in 1985.

The salient features of this report are the high mortality rate and the relatively high incidence of hemoltyic uremic

\section{TABLE 2}

Clinical and laboratory features of patients with hemolytic uremic syndrome

\begin{tabular}{lcccc}
\hline Patient & $\begin{array}{c}\text { Initial } \\
\text { episode } \\
\text { to HUS (days) }\end{array}$ & $\begin{array}{c}\text { Micro- } \\
\text { angiopathy }\end{array}$ & $\begin{array}{c}\text { Platelet count } \\
10^{\circ} / \mathrm{L}\end{array}$ & $\begin{array}{c}\text { Serum } \\
\text { creatinine } \\
(\mu \mathrm{mol} / \mathrm{L})\end{array}$ \\
\hline 2 & 5 & + & $238 / 188^{\circ}$ & $198 / 1022^{\circ}$ \\
4 & 6 & + & $420 / 77$ & $124 / 383$ \\
10 & 7 & + & $460 / 70$ & $90 / 121$ \\
11 & 9 & + & $238 / 88$ & $88 / 194$ \\
12 & 8 & + & $321 / 128$ & $82 / 180$ \\
17 & 8 & ++ & $218 / 46$ & $99 / 162$
\end{tabular}

HUS Hemolytic uremic syndrome; "Admission value: HUS value 
syndrome associated with the outbreak. The fact that an aged and otherwise ill patient population was involved is of prime importance. With two exceptions $(8,9)$, previously reported outbreaks have involved younger age groups. All have reported lower mortality rates. Food-borne transmission has been the common thread in all previous reports and this outbreak was no exception with the likely source being sandwiches served during lunch on September 5 (19). During the outbreak, there was epidemiological evidence of person to person transmission of the infectious agent as well as primary infection (19).

ACKNOWLEDGEMENTS: We gratefully acknowledge the collaboration and assistance of Dr Douglas Mills, Department of Pathology, St Joseph's Health Centre, London, Ontario and the assistance of Dr C. Krishnan, Department of Microbiology, University Hospital, London, Ontario in the preparation of this article. We also express our appreciation to the Department of Microbiology, University Hospital, London, Ontario for their work in identification of the E coli 0157: H7 pathogen and verotoxin during the outbreak.

\section{REFERENCES}

1. Fong J, Chadarevian J, Kaplan B. Hemolytic uremic syndrome, current concepts and management. Ped Clin N Am 1982:29:835-56

2. Spargo BH, Seymour AE, Ordonez NG. Hemolytic uremic syndrome in renal biopsy pathology with diagnostic and therapeutic implications. New York: John Wiley \& Sons, 1980;248-51.

3. Konowalchuk J, Speirs JI, Stavric S. Vero response to a cytotoxin of E coli. Infect Immunol 1977; 18:775-9.

4. Riley LW, Remis RS, Helgerson SD, et al. Hemorrhagic colitis associated with a rare E coli serotype. N Engl 1 Med 1983;308:681-5.

5. Remis RS, MacDonald KL, Riley LW,
There seems to have been a single causative organism involved in this outbreak as either Ecoli 0157:H7 or verotoxin was found in the stools of two-thirds of the patients admitted and no other potential pathogen was isolated.

While therapeutic intervention was not beneficial, beyond fluid replacement and general support, the outbreak evolved in a fashion that did not permit controlled and coordinated treatment and a role for early and specific plasma administration and/or antibiotic use should not be ruled out in a future outbreak.Epidemiologic evidence suggested that those patients receiving antibiotic

et al. Sporadic cases of hemorrhagic colitis associated with E coli 0157:H7. Ann Intern Med 1984; 101:624-6.

6. Wells JG, Davis BR, Wachsmuth K, et al. Laboratory investigation of hemorrhagic colitis outbreaks associated with a rare Escherichia coli serotype. J Clin Microbiol 1983:18:512-20.

7. Pai CH, Gordon R, Sims HV, et al. Sporadic cases of hemorrhagic colitis associated with Ecoli 0157:H7. Ann Intern Med 1984:101:738-42.

8. Stewart PJ, Desormeaux W. Chene J. Hemorrhagic colitis in a home for the aged - Ontario. Can Dis Weekly Rep 1983:9:29-32

9. Ryan CA, Tauxe RU, Hosek GW, et al. Escherichia coli 0157:H7 diarrhea in a nursing home: Clinical, epidemiological and pathological findings. J Inf Dis $1986 ; 154: 631-8$.

10. Hunter MI, MacDonald NE, Scheifele DW, et al. Escherichia coli gastroenteritis: Making sense of the new acronyms. Can Med Assoc J 1987; 136:241-4.

11. Sack RB. Enterohemorrhagic Escherichia coli. N Engl J Med 1987:317:1535-7. (Edit)

12. Gasser C, Gautier E, Steck A, et al. Hamolytisch-uramische syndrome: Bilaterale neirenrindennekrosen bei akuten erworbenen hamolytischen anemien. Schweiz Med Wochenschr 1955;85:905-9. therapy at the time of exposure were more likely to become ill through secondary infection (19).

The present authors' experience with these patients indicates that VTEC infections are a potentially life threatening illness especially in the elderly. It is worthwhile, therefore, underlining the importance of a high index of suspicion for these organisms being maintained in an institutional diarrheal outbreak. Early recognition of the causative organism allows early initiation of case isolation and epidemiological work to trace and eliminate the source of infection and thus limit institutional spread.

13. Kaplan BS, Drummond KN. The hemolytic uremic syndrome is a syndrome. N Engl J Med 1978;298:964-6.

14. Koster F, Levin J. Walker L, et al. Hemolytic uremic syndrome after shigellosis. Relation to endotoxinemia and circulating immune complexes. N Engl J Med 1978;298:927-33.

15. Karmali MA, Petric M, Steek BT, et al. Sporadic cases of hemolytic uremic syndrome associated with fecal cytotoxin and cytotoxin producing $E$ coli in stools. Lancet 1983;i:619-20.

16. Karmali MA, Petric M, Lim C, et al. E coli cytotoxin, hemolytic uremic syndrome and hemorrhagic colitis (C) Lancet 1983;ii:1299-300.

17. Karmali MA, Petric M, Lim C, et al. The association between idiopathic hemolytic uremic syndrome and infection by verotoxin-producing $E$ coli. J Inf Dis 1985; 151:775-82.

18. Neill AM, Agorti J, Rosen H. Hemorrhagic colitis with E coli 0157:H7 preceding adult hemolytic uremic syndrome. Arch Intern Med 1985;145:2215-7.

19. Carter AO, Borczyk AA, Carlson AK, et al. A severe outbreak of Escherichia coli 0157:H7-associated hemorrhagic colitis in a nursing home. N Engl J Med 1987:317:1496-500. 


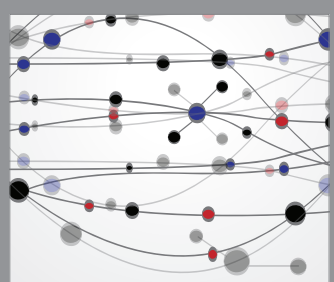

The Scientific World Journal
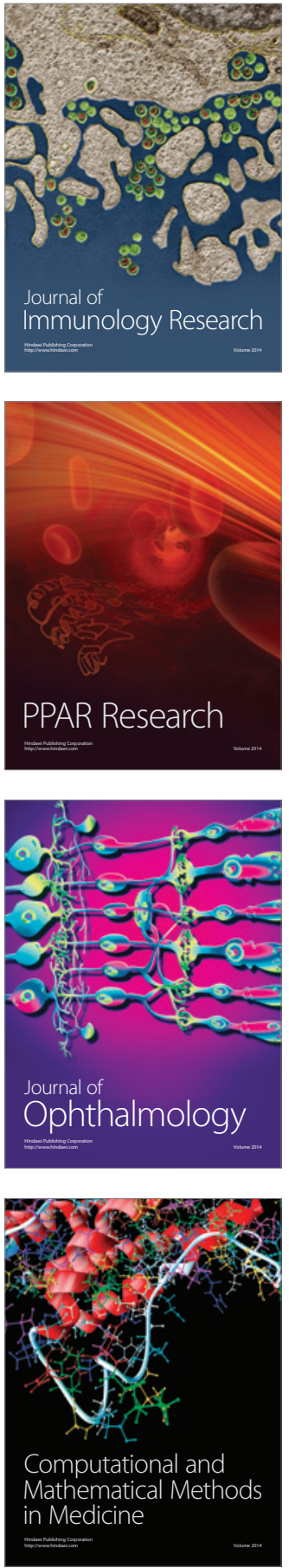

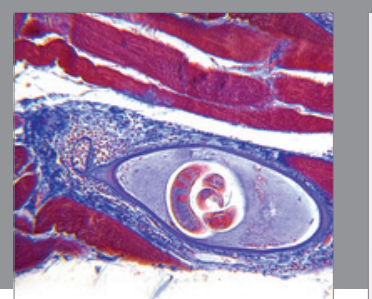

Gastroenterology Research and Practice

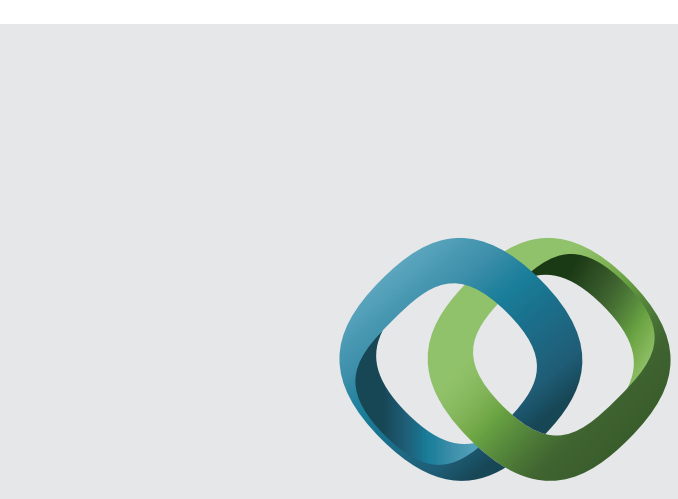

\section{Hindawi}

Submit your manuscripts at

http://www.hindawi.com
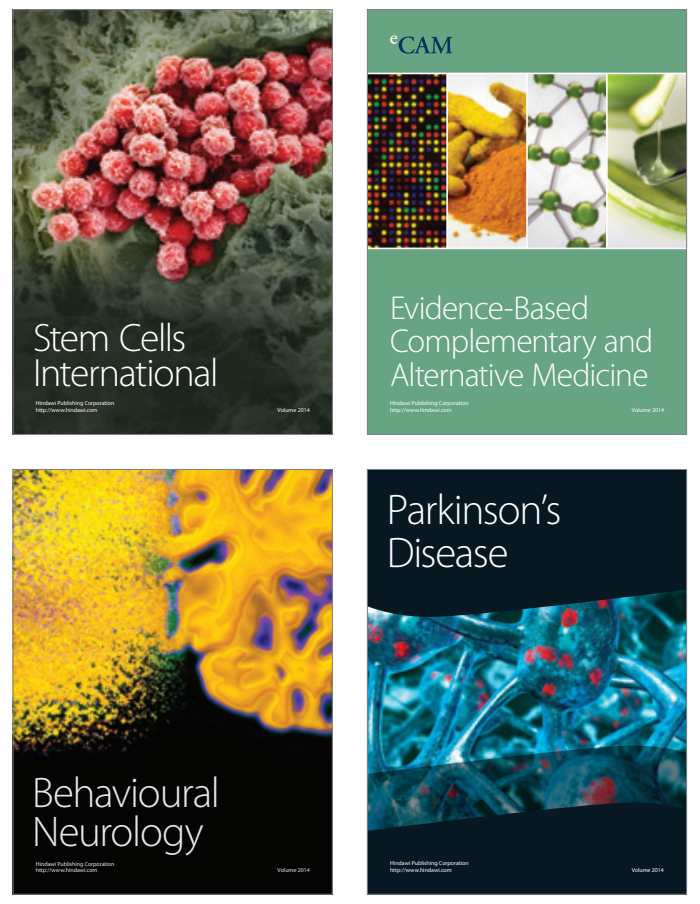
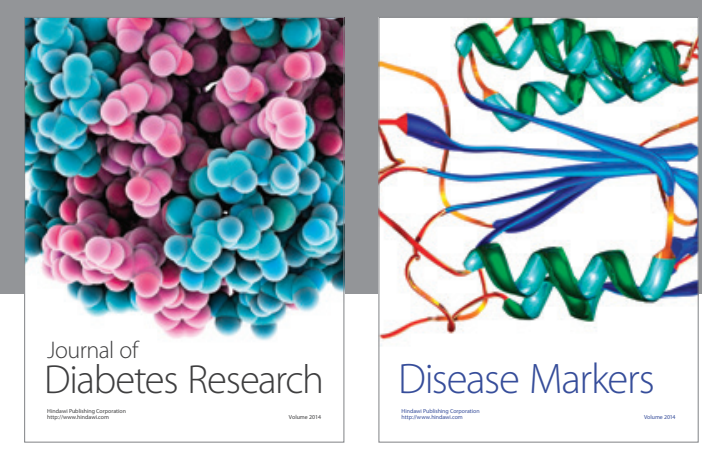

Disease Markers
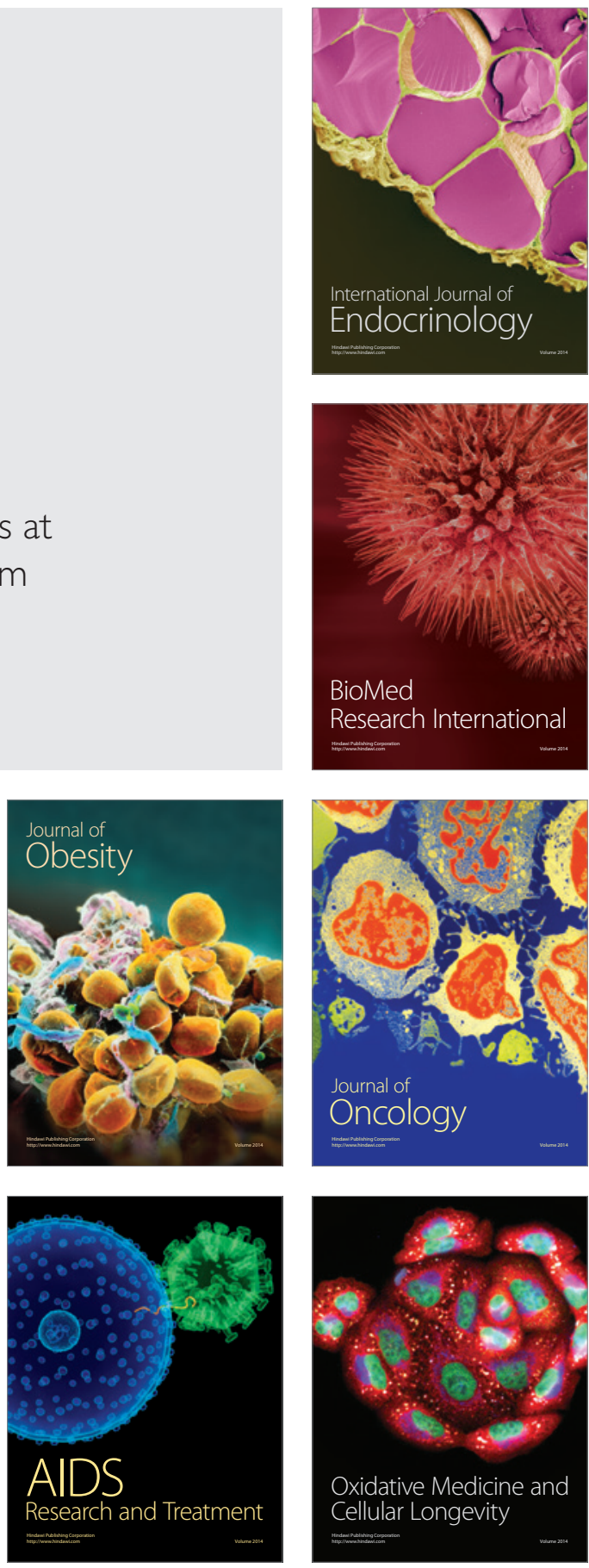